Published in final edited form as:

J Pharm Pract. 2013 October ; 26(5): 464-475. doi:10.1177/0897190013499521.

\title{
Epidemiology of Clostridium difficile Infection
}

Daryl D. DePestel, Pharm.D., BCPS-ID and

Clinical Scientific Director, Medical Affairs, Cubist Pharmaceuticals, Inc., 65 Hayden Ave, Lexington, MA 02421

David M. Aronoff, M.D., F.I.D.S.A.

Division of Infectious Diseases, Department of Internal Medicine, Department of Microbiology \& Immunology, University of Michigan Medical School, Ann Arbor, MI, 48109

David M. Aronoff: daronoff@umich.edu

\section{Abstract}

There has been dramatic change in the epidemiology of Clostridium difficile infection (CDI) since the turn of the $21^{\text {st }}$ Century noted by a marked increase in incidence and severity, occurring at a disproportionately higher frequency in older patients. Historically considered a nosocomial infection associated with antibiotic exposure, CDI has now also emerged in the community in populations previously considered low risk. Emerging risk factors and disease recurrence represent continued challenges in the management of CDI. The increased incidence and severity associated with CDI has coincided with the emergence and rapid spread of a previously rare strain, ribotype 027. Recent data from the U.S. and Europe suggest the incidence of CDI may have reached a crescendo in recent years and is perhaps beginning to plateau. The acute-care direct costs of CDI were estimated to be $\$ 4.8$ billion in 2008. However, nearly all the published studies have focused on CDI diagnosed and treated in acute-care hospital setting and fail to measure the burden outside the hospital, including recently discharged patients, outpatients, and those in longterm care facilities. Enhanced surveillance methods are needed to monitor the incidence, identify populations at risk, and characterize the molecular epidemiology of strains causing CDI.

\section{Keywords}

Clostridium difficile; Epidemiology; Risk Factors; Ribotype 027; Elderly

\section{INTRODUCTION}

Clostridium difficile is a Gram-positive, anaerobic, spore-forming bacillus that was first identified in 1978 as the predominate bacterial cause of antibiotic-associated diarrhea and pseudomembranous colitis (PMC). ${ }^{1}$ While the pathogenicity of $C$. difficile toward humans was discovered in relation to its ability to cause antibiotic-associated diarrhea and PMC, it is

*Corresponding author: Home mailing address: 7770 Brass Creek Drive, Dexter, MI 48130, Phone: 734.276.2227, Fax: 734.726.5005, daryl.depestel@cubist.com.

Financial disclosure information: D.D.D. is currently an employee of Cubist Pharmaceuticals, Inc. and owns company stock. The contents of this manuscript represent the opinion of the author and do not necessary represent the opinions of Cubist Pharmaceuticals, Inc. D.M.A. was supported by the National Institutes of Health grant 1U19AI090871. 
now known that the manifestations of CDI can range from asymptomatic colonization, to mild diarrheal illness, to more severe disease, including PMC, toxic megacolon, sepsis, and death. ${ }^{2}$ In the past 10-15 years, $C$. difficile infection (CDI) has emerged as an increasingly important infectious disease worldwide. Although $C$. difficile has historically been considered a nosocomial pathogen associated with antibiotic exposure, its epidemiology is rapidly changing. $C$. difficile infections have emerged in the community in populations previously considered low risk, such as healthy peripartum women, children, antibioticnaïve patients, and those with minimal or no recent healthcare exposure. ${ }^{3-6}$

Data from the U.S. and Europe suggest the incidence of CDI may have reached a crescendo in recent years and is leveling off or slightly declining. ${ }^{7-10}$ However, the overall incidence of CDI has increased to the point of surpassing rates of methicillin-resistant $S$. aureus infections in the some areas of the U.S. as the most common cause of healthcare-associated infection. ${ }^{11,12}$ Paralleling this increased prevalence there has also been a corresponding increase in morbidity and mortality associated with CDI, which has coincided with the emergence and rapid spread of a previously rare strain, known synonymously as polymerase chain reaction (PCR) ribotype 027, North American Pulse-field type 1 (NAP1), or restriction endonuclease analysis (REA) type BI, heretofore referred to as ribotype $027 .{ }^{13}$ Studies in North America and Europe have implicated the ribotype 027 strain in CDI outbreaks characterized by an increased incidence and severity, refractory to traditional therapy, and a greater risk of relapse. ${ }^{14-18}$ More recently, additional strains have been reported to cause CDI with increased severity and poor outcomes. ${ }^{19,20}$ The increased burden of CDI places a significant financial constraint on the healthcare system. The acute-care direct costs of CDI in the U.S. were estimated to be $\$ 4.8$ billion in $2008 .{ }^{21}$ However, the actual cost is likely higher when considering indirect costs associated the management of CDI. This review discusses the current epidemiology of CDI, including patient risk factors and future challenges.

\section{HISTORICAL PERSPECTIVE}

A clinical description of a CDI-like disease was possibly first reported by John Finney and Sir William Osler at Johns Hopkins Hospital on July $28^{\text {th }}, 1892 .{ }^{22}$ A 22 -year old female underwent gastric surgery for a cicatrizing ulcer and developed mild diarrhea ten days postoperatively. Her diarrhea progressed into frequent bloody stools and she expired 5 days later. Autopsy records indicated a "diphthertic colitis" was observed in the small bowel. ${ }^{22}$ Interestingly, while this occurred in the preantibiotic era, the patient had receive a boric acid stomach irrigation prior to surgery as a local antiseptic. ${ }^{22}$

In 1935, Hall and O'Toole first described Bacillus difficilis, a difficult to grow, obligate anaerobic, gram-positive, spore-forming, cytotoxin-producing rod isolated from the intestinal tract of healthy newborn infants. ${ }^{23}$ Eventually it was renamed Clostridium difficile, but because it had been isolated from healthy infants there was no reason to believe it had any deleterious effects in humans. Even today, it is well recognized that infants can be colonized with $C$. difficile, which can persist during the first 2 years of life. ${ }^{24}$ For decades $C$. difficile was not linked to PMC and little remained known about the organism, except that it was considered to be part of the normal intestinal ecology of infants. Notably, PMC, a 
hallmark of CDI, was rare before the widespread use of antibiotics in the last 1940s and early 1950s ${ }^{25}$ Subsequently, reports of antibiotic-associated diarrhea and PMC became much more frequent and antibiotic-resistant $S$. aureus was implicated as the causative organism based on routine stool culture. ${ }^{26}$

In 1974, Tedesco et al. identified a strong relationship between clindamycin and PMC, termed "clindamycin-colitis". 27 They conducted a prospective study of 200 consecutive clindamycin recipients and found that 21 percent developed diarrhea, which upon further endoscopic examination revealed that 50 percent had evidence of PMC. ${ }^{27}$ Later studies demonstrated that administration of vancomycin to hamsters was protective against clindamycin-colitis, suggesting that certain gut bacteria play a role in the pathogenesis of PMC. ${ }^{28}$ The concept at the time that broad-spectrum antibiotics were altering the indigenous gut microbiota and allowing for overgrowth of a pathogenic organism set the stage for our current understanding of CDI. In the late 1970s, an early notion that S. aureus was the major bacterial cause of antibiotic-associated PMC was fading and a series of investigations eventually led to $C$. difficile being reported as causative pathogen. Investigators initially reported a clostridial toxin was the cause of the cytopathic effect on the gut. ${ }^{29,30}$ In 1978, Bartlett et al. implicated toxin-producing $C$. difficile as a cause of PMC. ${ }^{1}$ Eventually, several investigators were able to isolate $C$. difficile from the stool of patients with PMC. ${ }^{31,32}$ During the next decade, research established epidemiologic data, clinical features, diagnostic tests, and effective therapies. By the late 1980s many believed CDI was well understood and could be effectively managed with available diagnostic and therapeutic modalities. ${ }^{33}$

Until the turn of the $21^{\text {st }}$ century CDI was largely viewed as a treatable complication of antimicrobial therapy and not viewed as a major public health threat. However, in the last decade CDI has reemerged as a serious infectious disease, occurring more frequently, with increased severity, and more refractory to standard therapy. This reemergence has led to a renewed interest in the changing epidemiology and outcomes of CDI.

\section{INCIDENCE AND DISEASE BURDEN}

C. difficile infection is the major identifiable cause of antibiotic-associated diarrhea and is responsible for 15-25 percent of all cases, with a marked increase in the incidence of CDI since the turn of the $21^{\text {st }}$ century. ${ }^{2}$ The reemergence of CDI, coupled with an increasingly vulnerable healthcare population has resulted in more frequent medical and surgical complications, added health care costs, and greater mortality. From 1996 to 2000, the reported incidence of CDI cases in acute care hospitals in the U.S. remained relatively stable at 30-40 discharges per 100,000 population, but nearly doubled to 60 discharges per 100,000 population in $2003 .{ }^{8}$ There was a significant upward trend from 2000-2003, with the largest increase in 2001. ${ }^{8}$ An increase in the number of patients with severe CDI and need for colectomy was noted in Quebec, Canada in 2002. ${ }^{16}$ Upon further investigation, it was discovered that the rate of CDI more than doubled from 65.6 to 156.3 per 100,000 population from 1991 to 2003, respectively. ${ }^{16}$ Additionally, the proportion of patients who had complicated cases (defined as development of megacolon, perforation, colectomy, shock requiring vasopressor support, mortality) increased from 7.1 to 18.2 percent $(P<0.001)$ and 30-day mortality increased from 4.7 to 13.8 percent $(P<0.001) .{ }^{16}$ By the turn of the 
millennium reports of a new epidemic were emerging in the U.S. 12,17,34,35 and Canada, ${ }^{15,25,36}$ followed by reports in Europe. ${ }^{37-39}$

Analysis of the Healthcare Cost and Utilization Project (HCUP) database, sponsored by the Agency for Healthcare Research and Quality, indicated that there was more than a 2.5-fold increase $(139,000$ to 349,000$)$ in the number of hospitals stays with any CDI discharge diagnoses in the U.S. from 2000-2008; a 3.5-fold increase $(32,800$ to 114,000$)$ was attributed to a principle diagnosis of CDI over the same period. ${ }^{7}$ However, after steady increases over the past decade, the number of CDI-related hospital stays appears to have leveled off between 2008 and 2010 40; albeit at historically high levels. There were 349,000 and 336,600 CDI-related hospital stays in the U.S. in 2008 and 2009, respectively; each year approximately one-third had a principle diagnosis of CDI. ${ }^{7}$ In 2009 CDI accounted for almost 1 percent of total admissions. ${ }^{7}$ Similar trends have been noted in parts of Europe since 2007, in fact recent data suggest the incidence of CDI may be declining in some areas. From 2007 to 2010, a 61 percent reduction in the incidence of CDI was observed in England. ${ }^{41}$ It is not entirely clear if the decreased incidence is due to the success of expanded prevention and control efforts, changes in the prevalence of epidemic strains (i.e., ribotype 027 ) or perhaps a combination of factors.

C. difficile infection disproportionately affects older patients with dramatic differences observed in those $\Varangle 65$ years of age, as evidenced by the several fold higher age-adjusted rate of CDI in this subpopulation. ${ }^{15,42}$ In the U.S. a total of 93 percent of deaths from CDI occurred in persons $\geq 65$ years of age and was reported as the $18^{\text {th }}$ leading cause of death in this age group in $2008 .{ }^{43}$ Recent analysis of the HCUP database indicates patients $\geq 85$ years of age have the highest rate (1,089 per 1000,000 population) of CDI hospitalizations, followed by patients $\Varangle 65$ years of age (465 stays per 1000,000 population). ${ }^{7}$ Collectively, those $\geq 65$ years of age represented 92 percent of CDI-related hospital stays in the U.S. in 2009. 7

While the epidemiology of CDI has changed in the past decade, one of the most notable changes has been the apparent increased incidence among populations in the community who were historically considered to be at low risk, such as healthy peripartum women, children, antibiotic-naïve patients, and those with minimal or no recent healthcare exposure. ${ }^{3-6}$ Data from North America and Europe suggest that approximately 20-27 percent of all CDI cases are community-associated, with an incidence of 20-30 per 100,000 population. ${ }^{44}$ The results of a population based-study evaluating the epidemiology of community-acquired CDI were recently published. ${ }^{45}$ The study evaluated all confirmed cases of CDI in a Minnesota county from 1991-2005 and compared community- vs. hospital-acquired cases of CDI. Hospital-acquired infection was defined if onset of symptoms occurred $>48$ hours after admission to, or $<4$ weeks after discharge from a healthcare facility. Community-acquired infection was defined if onset of symptoms occurred in the community or within 48 hours of admission to a hospital, provided symptom onset was $>12$ weeks after the last discharge from a hospital. A total of 385 definite CDI cases were identified; 157 (41 percent) were community-acquired. The incidence of community-acquired CDI increased 5.3-fold; from 2.8 to 14.9 per 100,000 person-years $(P<0.0 .001)$. Similarly, the incidence of hospital-acquired CDI increased 19.3-fold; from 2 
to 40.2 per 100,000 person-years $(P<0.0 .001)$. In contrast to those with hospital-acquired CDI, patients with community-acquired infection were younger (median age 50 vs. 72 years), likely to be female (72 vs. 60 percent), and had lower comorbidity scores. Those with community-acquired CDI were also less likely to have severe infection ( 20 vs. 31 percent), more likely to be antibiotic-naïve ( 22 vs. 6 percent), less likely to be on gastric acid suppressing therapy ( 22 vs. 47 percent), and less likely to have cancer (17 vs. 32 percent). No differences in recurrence rates ( $\sim 30$ percent) were noted between the two groups. The finding of this population based-study demonstrate that a significant proportion of CDI cases occur in the community and generally involve younger, less ill patients. The burden of CDI is usually evaluated in hospitalized patients and therefore, likely underestimates the burden of disease and overestimates its severity.

Recently the Centers for Disease Control and Prevention (CDC) launched an active, population-based surveillance for CDI through the Emerging Infections Program. ${ }^{46}$ One of the objectives is to describe the epidemiology of community-associated CDI (CA-CDI). Community-associated CDI cases were defined if a positive stool specimen was collected as an outpatient or within 3 days of an acute care admission in a patient without documentation of an overnight stay in a healthcare-facility in the prior 12 weeks. In 2010, a total of 10,342 CDI cases were identified from across the U.S, of which 3,269 (32 percent) were CA-CDI. The median age of CA-CDI cases was 52 years (range 1-93 years), and 61percent were female; 1 percent of whom was in the peripartum period. Greater than a quarter (27 percent) resulted in hospitalization within 7 days after a positive $C$. difficile stool sample. Intensive care unit admission within 7 days, colectomy and death were uncommon: 2, 0.3, and 0.9 percent, respectively. The recurrence rate was 9 percent; occurring a median of 26 days (range 14-56 days) after the positive $C$. difficile stool collection. The ribotype 027 strain was the most prevalent strain identified in the CA-CDI population.

Reports indicate the incidence of CDI among hospitalized children has also been increasing across the U.S. ${ }^{3,47-49}$ A retrospective cohort study of hospitalized children evaluated CDI at 22 freestanding children's hospitals in the U.S., from 2001-2006. ${ }^{3}$ The annual incidence increased over the study period from 2.6 to 4.0 cases per 1000 admissions (53 percent; $P=0.04$ ) and from 4.4 to 6.5 cases per 10,000 patient-days (47 percent; $P=0.06$ ). ${ }^{3}$ Similarly, a study utilizing the Healthcare Cost and Utilization Project Kids' Inpatient Database along with a second database, the National Hospital Discharge Survey, demonstrated a prominent increase in CDI-related hospitalizations, from 7.24 to 12.80 per 10,000 hospitalizations from 1997-2006, respectively. ${ }^{48}$ A second study utilizing numbers from the Healthcare Cost and Utilization Project Kids' Inpatient Database, also noted a significant increase in the number of CDI cases $(3,565$ to 7,$779 ; P<0.001)$ over the same time period. ${ }^{47}$ In this study, pediatric patients with CDI had an increased risk of death (adjusted odds ratio [OR], 1.20; 95\% confidence interval [95\% CI], 1.01-1.43, colectomy (adjusted OR, 1.36; 95\% CI, 1.041.79), a longer length of stay (adjusted OR, 4.34; 95\% CI, 3.97-4.83), and higher hospitalization charges (adjusted OR, 2.12; 95\% CI, 1.98-2.26), compared to those without CDI. ${ }^{47}$

Most studies describing the epidemiology of CDI in children involve hospitalized patients, which likely underestimates the burden of disease in this population. Hence, a recent 
population-based cohort study assessed the epidemiology of CDI in children from 19912009 in a county of Minnesota. ${ }^{49}$ A total of 92 cases of CDI were identified over the study period. The overall age- and sex- adjusted CDI incidence was 13.8 per 100,000 personyears, representing a significant 12.5 -fold increase, from 2.6 (1991-1997) to 32.6 per 100.000 (2004-2009) person-years; $P<0.001$. In the 12 weeks prior to CDI diagnosis, exposure to antibiotics and gastric acid suppression medication occurred in 78 and 20 percent of cases, respectively. The majority (75 percent) of CDI cases were considered CACDI according to Infectious Diseases Society of America/Society of Healthcare Epidemiology of America definitions. ${ }^{42}$ Similar to the overall population, the age and sex adjusted CA-CDI incidence was 10.3 per 100,000 persons, representing a significant 10.6fold increase, from 2.2 (1991-1997) to 23.4 per 100.000 (2004-2009) persons; $P<0.001$. In 86 percent of the CA-CDI cases, patients had an outpatient or an emergency department visit in the three months, while 11 percent did not have any healthcare exposure in the 12 week prior to CDI onset. These findings are similar to a recent CDC report, noting a majority of patients with CA-CDI had healthcare exposure prior to CDI. ${ }^{50}$

As noted, it is important to remember that most of the published data on incidence (and economic costs) represent CDI diagnosed in the acute-care hospital setting and therefore likely underestimates the total burden of CDI on the overall healthcare system. As an example, mandatory reporting of CDI in hospitals and nursing homes in Ohio during 2006 indicated the rate of initial cases was higher in hospitals compared to nursing homes; 6.47.9 vs. $1.7-2.9$ cases per 10,000 patient-days; respectively. ${ }^{51}$ However, it was estimated that more 60 percent (11,200 of 18,200 cases) of the total burden of healthcare-associated CDI cases may have their onset in long-term care facilities. ${ }^{51}$

Analysis of the HCUP database reported among patients diagnosed of CDI during hospitalization in 2009, 4.8 percent were readmitted within 30 days with CDI as a principle diagnosis, 12.8 percent were readmitted with CDI listed as either principle or secondary, compared to 29.1 percent all-cause readmission. ${ }^{40}$ Overall, 41.5 percent of CDI index stays resulted in discharge to long term care, and readmission rates for these patients were higher than for patients overall. ${ }^{40}$ Most astonishing was the nearly half (49 percent) of these patients were readmitted (all-cause readmission) to the hospital within 90 days. ${ }^{40}$

C. difficile infection places a significant economic burden on the healthcare system. The acute-care direct costs of CDI in the U.S. were estimated to be $\$ 4.8$ billion in $2008 .{ }^{21}$ Analysis of the HCUP database indicate the average cost for a CDI stay was $\$ 24,400$ in $2009 .{ }^{7}$ While the aggregate cost for all CDI stays was $\$ 8.2$ billion; $\$ 1.1$ vs. $\$ 7.1$ billion for principle and secondary diagnosis, respectively, or 2.3 percent of all hospital costs in the U.S. ${ }^{7}$ Hospital stays during which CDI was a secondary diagnosis were more than twice as long as those with CDI as a principle diagnosis (16.0 vs. 6.9 days) and costs were more than three times higher $(\$ 31,500$ vs. $\$ 10,100) .{ }^{7}$ However, the actual cost is likely higher and more data are needed to assess healthcare cost when considering indirect costs associated the overall management of CDI, including recurrences. Furthermore, nearly all the published studies have focused on CDI diagnosed and treated in acute-care hospitals and fail to measure the burden outside the hospital, including recently discharged patients, outpatients, and those in long-term care facilities. ${ }^{21,50}$ 


\section{DISEASE SEVERITY AND RECURRENCES}

Over the last decade there has been reports suggesting not only a significant increase in the incidence, but also in the severity of CDI resulting in increased colectomies and death. ${ }^{16,17,52,53}$ Patients with CDI hospital stays are more severely ill than hospitalized patients in general and are at increased risk of morbidity and mortality. A recent multicenter study in the U.S. reported a colectomy rate of 8.7 per 1,000 CDI cases from 2000-2006. ${ }^{54}$ Overall, there was no significant change in the CDI-related colectomy rate over the study period. Risk factors for colectomy included age $\geq 65$ years (OR, 1.6; 95\% CI, 1.0-2.6), community-onset CDI (OR, 3.4; 95\% CI, 2.0-5.5, and significant variability in colectomy rates was noted among institutions. ${ }^{54}$ While rates of colectomy remain low, mortality has steadily increased over time. During outbreaks of CDI, all-cause mortality has been reported to be between 15-25 percent within 30 days. ${ }^{15,25,55,56}$ Attributable mortality among patients with CDI is difficult to estimate given those affected typically are of advance age and have multiple underlying comorbid conditions. However, data from the U.S. vital records indicate an increasing trend in CDI-related mortality. The number deaths with CDI listed as the primary cause of death increased more than 9-fold; 793 to 7483 in the U.S. from 1999 to 2008, respectively. ${ }^{43}$ The age-adjusted death rate for CDI increased from 2.0 to 2.3 deaths per 100,000 population from 2007 to 2008 , respectively; representing a 15 percent increase. ${ }^{43} \mathrm{~A}$ recent study examined the trends in gastroenteritis-associated deaths across the U.S. between 1999 and 2007. ${ }^{57}$ C. difficile infection was the main contributor to gastroenteritis-associated deaths over the study period. $C$. difficile mortality increased 5-fold from 10 to 48 per 1,000,000 person-years from 1999-2000 to 2006-2007 ( $<<0.001$ ), respectively. ${ }^{57}$ In 2009, analysis of HCUP data indicated patients with CDI had higher severity of illness scores, were at higher risk of major or extreme loss of function, and were at higher risk of mortality. ${ }^{7}$ Approximately 9.1 percent of CDI stays ended in death, compared with less than 2 percent for all other inpatients. ${ }^{7}$ A Canadian surveillance study reported the attributed mortality rate of healthcare-associated CDI increased almost 4-fold between 1997 and 2005 (5.7 vs. 1.5 percent; $\mathrm{p}<0.001$ ). ${ }^{55}$ The highest rates of attributed mortality was among those $>65$ years of age, representing 3.5 -fold increase compared to those $18-64$ years of age; 7.3 vs. 2.2 percent; $p<0.001$, respectively. ${ }^{55}$ A recent multicenter cohort study from the Netherlands evaluated CDI-related mortality in an endemic setting from 2006 to 2009. ${ }^{58}$ All cause-mortality was 13 percent after 30 days and 37 percent after 1 year. Compared to control patients, CDI patients has a 2.5-fold increase (Hazard ratio, 2.5; 95\% CI, 1.4 - 4.3) in 30-day mortality rate after adjusting for age, sex and underlying comorbid conditions. ${ }^{58}$ Encouraging data have recently emerged from the United Kingdom. ${ }^{41}$ Coinciding with the declining incidence of CDI in recent years, mortality rates have also been noted since 2007. The number of death certificates mentioning CDI decreased by 70.5 percent from 7,916 to 2,335 instances between 2007 and 2010. ${ }^{41}$ Although further investigations are needed to verify these findings elsewhere in Europe and North America. Nevertheless, these data collectively highlight the considerable disease burden and clinical impact of CDI on patient outcomes.

The increasing trend in morbidity and mortality has been noted since the start of the $21^{\text {st }}$ Century eventually lead to the recognition of an emerging, previously rare strain, ribotype 
027. ${ }^{13,14,17,25}$ This epidemic strain has become endemic in many North American healthcare settings. ${ }^{14,25,59}$ It has been widely reported that the ribotype 027 strain is more virulent or "hypervirulent" compared to other pathogenic isolates of CDI. ${ }^{13,14}$ More recently, other genotypes including ribotypes $078 / 126,056$, and 018 have been reported to be associated with more complicated disease outcomes. ${ }^{60}$ Several microbial characteristics have been attributed to possible hypervirulence, including mutations in the regulatory gene $t c d C$ causing hyperproduction of toxins A and B, production of a binary toxin, antibiotic resistance, improved toxin binding to target cells, increased sporulation, and mutations in surface layer proteins that increase its adherence to intestinal epithelium. ${ }^{44,61}$

While beyond the scope of this review, the term "hypervirulent" and the notion that certain ribotypes cause more severe disease is currently an active matter of debate. ${ }^{60,62-65}$ Despite clear epidemiological associations between infection with ribotype 027 (and other) strains with adverse outcomes, a confounding factor is that such "hypervirulent" strains of $C$. difficile tend to infect hospitalized, older adults who are intrinsically more vulnerable to doing poorly upon acquiring CDI. ${ }^{18,56,66}$ When a particular ribotype of $C$. difficile (for example 027) disproportionately infects older adults in the hospital or long term care facility, including patients with declining functional status and/or multiple comorbidities, it is not surprising to find an association between that particularly strain of $C$. difficile and poor clinical outcomes when compared to younger, healthier patients disproportionately infected with other ribotypes. Controlling for such differences in host factors has been difficult and needs to be better accomplished in future, prospective studies. In addition, because of intensive efforts to reduce the burden of CDI over the past decade it is challenging to draw conclusions about the impact of bacterial ribotypes on disease incidence and severity without adjusting for shifts in practice over time. For example, recent studies that have tied the waning of ribotype 027 strains with simultaneous improvements in clinical outcome have not adjusted for changes in diagnostics, CDI treatment, antimicrobial stewardship, and infection control that occurred over the same period and could strongly impact disease severity. ${ }^{41}$ Thus, while "hypervirulent" ribotypes of $C$. difficile might exist, the absolute risk for severe CDI posed by such strains remains to be clearly defined and requires further, well-controlled, prospective studies.

Disease severity is generally an initial concern at the time of diagnosis, whereas recurrence of symptoms, as a consequence of relapse of the original infection (i.e., endogenous persistence of the same strain) or reinfection (i.e., acquisition of a new strain from an exogenous source), is an ongoing challenge over the continuum of care. Recurrence requiring retreatment continues to be one of the greatest challenges in the management of CDI. Historically, it has been reported that 12-24 percent of patients experience at least one recurrence and the risk of further recurrences increases to 50-65 percent if a patient has had more than two prior episodes. ${ }^{67} \mathrm{~A}$ subset of patients experience chronic relapsing CDI with multiple recurrences. ${ }^{68}$ Most recurrences occur with the first 30 days after completing a course of CDI therapy. ${ }^{69}$ Importantly, recurrence does not appear to be a consequence of $C$. difficile resistance to metronidazole or vancomycin. ${ }^{69}$ However, the cause of recurrent CDI is not completely understood and several mechanisms have been hypothesized including new or continued disturbances in gut microbiota with subsequent loss of colonization 
resistance, persistence of $C$. difficile spores in the gastrointestinal tract, a defective host immune response to $C$. difficile and/or its toxins or reinfection with a new strain. ${ }^{42,68,70-73}$ Recurrent CDI significantly increases the overall burden of disease on patients, as well as the healthcare system. It also increases the need for clinical evaluation (i.e., office visits, etc.), prolongs hospitalization, increases the cost of care and decreases the quality of life associated with repeated episodes of diarrhea ${ }^{69,70}$ Additionally, patients with recurrent CDI can serve as a reservoir for infection of other patients who share the same environment. ${ }^{69} \mathrm{~A}$ challenge to epidemiological studies of CDI is the difficulty discriminating relapse from reinfection on the basis of common typing schemes (e.g., ribotyping), since the same strain type can cause either reinfection or relapse. This is particularly problematic in patients who are hospitalized in an environment enriched with one or more predominant strain types. Whole genome sequencing or other highly discriminatory techniques will be needed to surmount this challenge in future studies. ${ }^{74}$

\section{PATIENT RISK FACTORS}

Several important patient risk factors for CDI have been identified and are summarized in Table 1. A significant patient risk factor for CDI is recent healthcare exposure. . $^{9}, 42,50,70,75$ Frequent hospitalization and increased length stay have been identified as risk factors for CDI. ${ }^{9}$ Data from the CDC's Emerging Infections Program in 2010 determined that 94 percent of CDI cases were associated with receiving healthcare, despite 75 percent of cases occurring outside the hospital, including in recently discharged patients, outpatients, and those in long-term care facilities. ${ }^{50}$ It has been well documented that $C$. difficile is spread by the fecal-oral route; spores as well as the vegetative form, can persist on fomites and environmental surfaces for months. ${ }^{50}$ Patients are exposed through contact with the healthcare environment or healthcare workers hands, stressing the importance of infection control and prevention efforts, in the acute care setting and in other associated healthcare environments as well.

Antibacterial exposure is a dominant risk for the development of CDI. Nearly every antibacterial has been associated with the development of CDI, including ironically metronidazole and vancomycin. ${ }^{76}$ The indigenous gut microbiota functions to protect against colonization or infection by pathogenic organisms, including $C$. difficile; known as "colonization resistance". ${ }^{72}$ Antibacterials can disrupt the competitive balance or homeostasis in the gut microbiota and promote the overgrowth of $C$. difficile, serving as major step in the development of CDI. ${ }^{72}$ Recurrent CDI after treatment with vancomycin or metronidazole, to some extent, is thought to be related to the ability of these antibiotics to disrupt the gut microbiota. ${ }^{69,77,78}$ These therapies not only inhibit $C$. difficile, but also other bacterial communities, thereby leading to loss of colonization resistance. ${ }^{69,77,78}$ In some instances, this allows germination of $C$. difficile spores and proliferation of vegetative cells in the gastrointestinal tract, causing a re-emergence of $C$. difficile populations leading to recurrence. ${ }^{78}$

Several antibacterial classes appear to increase the risk compared to others, including clindamycin, cephalosporins and fluoroquinolones. ${ }^{79,80}$ It is important to keep in mind the relative risk of a particular antibiotic and its association with CDI depends on the local 
prevalence of strains that are highly resistant to a given antimicrobial agent. ${ }^{42}$ For instance, clindamycin has been implicated as a risk for CDI, particularly with the "J strain" (REA type J7/9) which is resistant to clindamycin and was responsible for large outbreaks in the early 1990s. ${ }^{81}$ More recently, fluoroquinolone use has been implicated in outbreaks caused by the ribotype 027 strain, corresponding with a marked increase in fluoroquinolone resistance in this strain. ${ }^{14,17}$ Cumulative antibiotic exposure via dose, use of multiple antibacterial agents, and increased days of antibiotic exposure all contribute to the risk of CDI. ${ }^{2,80}$ Alternatively, limited exposure, such as a single-dose antibacterial exposure for surgical prophylaxis also increases the risk of both $C$. difficile colonization and infection. ${ }^{42,71,82}$ Some investigators have hypothesized the increased incidence of CDI in young, healthy peripartum women may be a result of exposure to antibacterial prophylaxis associated with Cesarean sections. ${ }^{83}$

Exposure to antibacterials not only increases the risk for CDI during receipt of antibacterial therapy, but also in the three months after cessation of therapy; with the highest risk during the first month after antibacterial therapy. ${ }^{79}$ Importantly, receipt of antibacterials during and after treatment of CDI has been associated with lower cure rates, prolonged time to diarrhea resolution, and a trend toward recurrent $\mathrm{CDI} .{ }^{77}$ Similarly, a recent retrospective study demonstrated receipt of antibacterials within 30 days after CDI therapy was significantly associated with the 90-day risk of recurrence (OR, 4.14; 95\% CI, 2.00-8.55) after adjusting for age, disease severity, and recent hospital or intensive care unit stay. ${ }^{71}$ This findings highlight the important need for antimicrobial stewardship and the judicious use of antimicrobial agents. This is especially true in lieu of recent findings that up to 26 percent of patients with a current or a recent history of CDI receive unnecessary and potentially avoidable antimicrobial exposure. ${ }^{84}$ Antimicrobial stewardship efforts should be an essential component of any intervention aimed at reducing the risk of CDI.

The role of gastric acid suppression agents, such as proton pump inhibitors (PPIs) and histamine-2 receptor antagonists (H2RAs) has been associated with an increased risk of CDI. ${ }^{42,85-87}$ While the precise biological basis for this association has not been fully elucidated, several hypothesis have been investigated. Decreased gastric acidity could lead to inadequate sterilization of ingested organisms, including C. difficile, resulting in increased colonization of the normally sterile upper gastrointestinal tract. ${ }^{88,89}$ Acid suppressing agents may also contribute to disruption of the indigenous gut microbiota, resulting in bacterial colonization of the stomach or upper small intestine, thereby promoting an environment conducive for $C$. difficile. ${ }^{90}$ It has also been postulated that bile salts may have a role in stimulating the conversion of $C$. difficile spores to the vegetative phase, and alterations in gut microbiota markedly increases the luminal concentrations of unconjugated bile acids. ${ }^{89,91}$ Lastly, studies also suggest PPIs may have an effect on intestinal neutrophil activity, which may interfere with defense mechanisms protective against CDI. ${ }^{92-94}$

In February 2012, the U.S. Food and Drug Administration issued a drug safety communication noting a possible association between the use of PPIs and CDI. ${ }^{87}$ The FDA reviewed 28 observational studies, 23 of which demonstrated a higher risk of CDI associated with PPI exposure. Most of the studies reviewed found the risk of CDI ranged from 1.4 to 2.75-fold higher among those exposed to PPIs. ${ }^{87}$ Two recently published meta-analyses both 
found an overall increased risk of CDI with PPI use. ${ }^{85,86}$ One of which demonstrated a 65 percent (summary risk estimate, 1.69; 95\% CI, 1.395-1.974 increase in the incidence of CDI among patients exposed to PPIs. ${ }^{85}$ While the other demonstrated an association between PPI use and an increased risk of developing CDI (OR, 1.74; 95\% CI, 1.47-2.85). ${ }^{86}$ Furthermore, an association between risk of recurrent CDI and PPI use was also demonstrated (OR, 2.51; 95\% CI, 1.16-5.44). ${ }^{86}$ Equally important, concomitant use of PPIs and antibiotics conferred a greater-risk (OR 1.96; 95\% CI, 1.03-3.70) than either treatment alone. ${ }^{86} \mathrm{H} 2 \mathrm{RAs}$ appeared to carried a lower-risk (OR, 0.70; 95\% CI, 0.53-0.97) compared with PPIs. ${ }^{86}$ While it is recognized these studies have limitations, it has been well documented that the effectiveness of PPIs for the treatment of upper gastrointestinal disorders has led to their overutilization in multiple treatment arenas, exposing patients to an increasing number of potential risks. ${ }^{95} \mathrm{In}$ lieu of the potential increased risk of CDI, the rational and prudent use of acid suppressing agents should be encouraged.

The patient's ability to produce an adequate immune response may be a key risk for CDI development and recurrence. ${ }^{70,96-98}$ In adults, the ability to produce antitoxin antibodies may be an important determinant leading to colonization versus active infection. ${ }^{61,97,98}$ Individuals that fail to produce sufficient quantities of immunoglobulin $\mathrm{G}(\mathrm{IgG})$ directed against toxin A are more likely to develop CDI and may also be at higher risk for recurrences. ${ }^{97,98}$ Other investigations have demonstrated that patients with a common single-nucleoside polymorphism in the -251 region of the interleukin (IL)-8 gene promoter are at increased risk for CDI. ${ }^{99}$

Advanced age is an important risk factor as evident by the disproportionate incidence of CDI in older patients, as noted above. The particular reasons for this association are likely multifactorial, including diminished immune response, increased comorbidities, and increased exposure to antibacterials and the healthcare environment. ${ }^{42,70}$

Cancer chemotherapy has also been shown to be a risk, independent of antibiotic exposure. ${ }^{42,100}$ Several chemotherapeutic agents have been implicated, including carboplatin, cisplatin, cyclophosphamide, doxorubicin, methotrexate, topotecan, paclitaxel, vinorelbine, and 5-fluorouracil, as well as others. ${ }^{100}$ The mechanism is thought to be a result of the antimicrobial activity of the chemotherapeutic agent and subsequent alterations in gut microbiota. ${ }^{42,100}$ Additional possible mechanisms include severe inflammatory changed induced by chemotherapy, intestinal necrosis promoting an anaerobic environment within the gastrointestinal tract, decreased degradation of $C$. difficile toxins and delayed reestablishment of indigenous microbiota. ${ }^{100}$

Populations with underlying chronic comorbid conditions, including those with chronic kidney disease, ${ }^{101}$ human immunodeficiency virus (HIV), ${ }^{42,102}$ solid organ ${ }^{103,104}$ or hematopoietic stem cell transplantation, ${ }^{100}$ and inflammatory bowel disease ${ }^{105}$ all appear to be at an increased risk of developing CDI. It is not entirely clear if these patients are at specific increased risk because of their underlying immunosuppression, exposure to specific medications, frequent exposure to antimicrobials, frequent and prolonged exposure to the healthcare environment, or some combination of factors. 
Risk factors for CA-CDI have not been fully elucidated. ${ }^{46}$ While increased exposure to antibacterial agents could be an important factor, there have been reports of CA-CDI in the absence of antibacterial exposure. ${ }^{106,107}$ As previously discussed, the use of gastric acidsuppressive agents could also be a potential risk factor. Interestingly, a recent study demonstrated the odds of developing CDI were 80 percent greater in current smokers and 33 percent greater in former smokers compared to nonsmokers. ${ }^{108}$ The study included those $>50$ years of age and CDI diagnosed both in the inpatient and outpatient setting. Increased transmission of $C$. difficile in the community could play a role. $C$. difficile has been isolated from the environment in outpatient healthcare areas and daycare centers, possibly serving as a reservoir for transmission. ${ }^{46}$ It has been suggested that exposure to household contacts with CDI and children less than 2 year of age, a group that is known to be highly colonized with $C$. difficile, could serve as a potential reservoir for transmission. ${ }^{5,24,109}$ Lastly, it has been hypothesized that retail food products and domestic animals could serve as potential source of $C$. difficile exposure, ${ }^{110}$ however, as with other possible factors further research needs to be conducted better understand risk factors for CA-CDI.

As previously mention, recurrent CDI represents one of the greatest challenges in the current management of CDI. Risk factors for recurrence and those for an initial episode are not necessarily mutually exclusive (Table 1). Several risk factors that initially predispose a patient to CDI remain an ongoing problem. A predominant risk factor is an episode of initial recurrence. ${ }^{20}$ Studies have demonstrated that the risk of recurrence more than doubles after two or more recurrences. ${ }^{111,112}$ Individuals that lack of a host response to produce sufficient quantities of antibodies directed against toxin A and those individuals with a common single-nucleoside polymorphism in the -251 region of the interleukin- 8 gene promoter may have an increased risk for recurrences. ${ }^{96-98}$ The risk of recurrences increases with advanced age with those patients $\succ 65$ year of age at highest risk. ${ }^{69,70,73}$ Disruption of the gut microbiota and loss of colonization resistance has been investigated ${ }^{72}$ as a risk factor recurrence and provides the biological basis for the successful use of fecal microbiota transplantation. ${ }^{113}$ Other risk factors for recurrence include concurrent use of antibiotics for non-CDI, acid suppressing agents, exposure to the healthcare environment, and underlying chronic comorbidities. ${ }^{69-71,73,77}$

\section{FUTURE CHALLENGES}

Our knowledge of CDI continues to evolve, challenging our understanding of CDI epidemiology. The need for standardized definitions and surveillance methods to detect outbreaks, assess disease trends, and facilitate comparison of CDI rates across healthcare institutions was recognized earlier this decade with the increased incidence and severity of CDI. ${ }^{44}$ Consensus recommendations for surveillance, including case definitions, were published in 2006 by the European Centre for Disease Prevention and Control (ECDC) ${ }^{39}$ and in 2007 by the CDC. ${ }^{114}$ While there have been improvements in surveillance of CDI in recent years, there is still a considerable lack of timely epidemiologic data and more needs to be accomplished. Gaining a better understanding of the incidence of CDI and the number of new cases that arise each year is fundamental to understanding the spread of $C$. difficile within healthcare facilities, within the community, and from other reservoirs of infection. ${ }^{115}$ National surveillance programs are vital to monitor the incidence, identify populations at 
risk, and characterize the molecular epidemiology of strains causing CDI. ${ }^{44}$ Lastly, given the shift in risk factors in the community setting, epidemiological studies that only utilize data from the acute care hospital setting under reports a significant proportion of CDI cases, skewing severity data and under representing the economic burden of the disease. ${ }^{45}$

Another challenge to our understanding of CDI epidemiology is the rapidly changing laboratory diagnostic approaches to CDI. ${ }^{9,44}$ The enzyme immunoassay (EIA) for detection of toxins A and B has been the most widely used laboratory test for CDI diagnosis, however, EIAs are known to have suboptimal sensitivity and specificity. ${ }^{116}$ More recently, polymerase chain reaction (PCR) assays, which detect the $C$. difficile genes involved with toxin production, have increased in popularity and offer higher sensitivity and specificity and more rapid turnaround time compared to EIAs. ${ }^{116}$ Some have advocated for a 2- or 3step testing algorithm utilizing various methods to improve diagnostic yield. ${ }^{117}$ However, variability in laboratory testing methodology will likely influence CDI rates. Institutions that have implemented PCR assay based screening for CDI have reported 2- to 3-fold increases in rates. ${ }^{44,118}$ Unless adjustments based on methodology and population prevalence are considered, hospitals participating in public reporting of CDI rates will be at a disadvantage for performing the most sensitive testing methodologies. ${ }^{117}$ There is active controversy about whether PCR should be a stand-alone diagnostic tool for CDI, since this can detect colonization in addition to infection, potentially resulting in overtreatment and overreporting. ${ }^{119}$ In addition, PCR might diagnose very mild cases of CDI that might resolve without therapy. ${ }^{120}$ Patients diagnosed only on the basis of PCR may have fewer complications and less severe disease than patients diagnosed on the basis of toxin detection, though this is controversial. ${ }^{119-121}$ Therefore, more research is warranted. Nevertheless, PCR is advocated in recent guidelines for use in the diagnosis of CDI. ${ }^{116}$

\section{SUMMARY}

In the past 10-15 years, $C$. difficile infection (CDI) has reemerged as an increasingly important infectious disease worldwide. The dramatic increase in the incidence of CDI, coupled with an increasingly vulnerable healthcare population has resulted in more frequent medical and surgical complications, added health care costs, and greater mortality. Furthermore, CDI is now increasingly being recognized in patient populations previously considered to be at low risk.

After steady increases over the past decade, the number of CDI-related hospital stays appears to have plateaued in recent years. It is not entirely clear if the decreased incidence is due to the success of expanded prevention and control efforts, changes in the prevalence of epidemic strains (i.e., ribotype 027) or perhaps a combination of factors. Emerging risk factors and disease recurrence represent continued challenges in the management of CDI. The acute-care direct costs of CDI were estimated to be $\$ 4.8$ billion in 2008. However, the actual cost is likely higher when considering indirect costs associated with the overall management, including treating recurrences. Nearly all the published studies have focused on CDI diagnosed and treated in acute-care hospital setting and fail to measure the burden outside the hospital, including recently discharged patients, outpatients, and those in longterm care facilities. Enhanced surveillance methods are needed to monitor the incidence, 
identify populations at risk, and characterize the molecular epidemiology of strains causing CDI.

\section{References}

1. Bartlett JG, Chang TW, Gurwith M, et al. Antibiotic-associated pseudomembranous colitis due to toxin-producing clostridia. N Engl J Med. 1978; 298:531-534. [PubMed: 625309]

2. Bartlett JG, Gerding DN. Clinical recognition and diagnosis of Clostridium difficile infection. Clin Infect Dis. 2008; 46(Suppl 1):S12-S18. [PubMed: 18177217]

3. Kim J, Smathers SA, Prasad P, et al. Epidemiological features of Clostridium difficile-associated disease among inpatients at children's hospitals in the United States, 2001-2006. Pediatrics. 2008; 122:1266-1270. [PubMed: 19047244]

4. Centers for Disease Control and Prevention. Surveillance for community-associated Clostridium difficile - Connecticut, 2006. MMWR Morb Mortal Wkly Rep. 2008; 57:340-343. [PubMed: 18385641]

5. Wilcox MH, Mooney L, Bendall R, et al. A case-controlled study of community-associated Clostridium difficile infection. J Antimicrob Chemother. 2008; 62:388-396. [PubMed: 18434341]

6. Centers for Disease Control and Prevention (CDC). . Severe Clostridium difficile-associated disease in populations previously at low risk-four states, 2005. MMWR Morb Mortal Wkly Rep. 2005; 54:1201-1205. [PubMed: 16319813]

7. Lucado, J.; Gould, C.; Elixhauser, A. [Accessed 8 January 2013.] Clostridium difficile infections (CDI) in hospital stays, 2009. Healthcare Cost and Utilization Project, Agency for Healthcare Research and Quality. Statistical brief \#124. Available at: http://www.hcup-us.ahrq.gov/reports/ statbriefs/sb124.pdf

8. McDonald LC, Owings M, Jernigan DB. Clostridium difficile infection in patients discharged from US short-stay hospitals, 1996-2003. Emerging Infectious Diseases. 2006; 12:409-415. [PubMed: 16704777]

9. Freeman J, Bauer MP, Baines SD, et al. The changing epidemiology of Clostridium difficile infections. Clin Microbiol Rev. 2010; 23:529-549. [PubMed: 20610822]

10. Elixhauser, A.; Jhung, MA. [Accessed 8 January 2013.] Clostridium difficile-Associated Disease in U.S. Hospitals, 1993-2005. Healthcare Cost and Utilization Project, Agency for Healthcare Research and Quality. Statistical brief \#50. Available at http://www.hcup-us.ahrq.gov/reports/ statbriefs/sb50.pdf

11. Miller BA, Chen LF, Sexton DJ, et al. Comparison of the burdens of hospital-onset, healthcare facility-associated Clostridium difficile Infection and of healthcare-associated infection due to methicillin-resistant Staphylococcus aureus in community hospitals. Infect Control Hosp Epidemiol. 2011; 32:387-390. [PubMed: 21460491]

12. Zilberberg MD, Shorr AF, Kollef MH. Growth and geographic variation in hospitalizations with resistant infections, United States, 2000-2005. Emerg Infect Dis. 2008; 14:1756-1758. [PubMed: 18976563]

13. Warny M, Pépin J, Fang A, et al. Toxin production by an emerging strain of Clostridium difficile associated with outbreaks of severe disease in North America and Europe. Lancet. 2005; 366:1079-1084. [PubMed: 16182895]

14. McDonald LC, Killgore GE, Thompson A, et al. An epidemic, toxin gene-variant strain of Clostridium difficile. N Engl J Med. 2005; 353:2433-2441. [PubMed: 16322603]

15. Pépin JL, Valiquette ME, Clossette B. Mortality attributed to nosocomial Clostridium difficileassociated disease during an epidemic caused by a hyperviluent strain in Quebec. CMAJ. 2005; 173:1037. [PubMed: 16179431]

16. Pépin JL, Valiquette ME, Alary ME, et al. Clostridium difficile-associated diarrhea in a region of Quebec from 1991-2003: a changing pattern disease severity. CMAJ. 2004; 17:466-472. [PubMed: 15337727]

17. Muto CA, Pokrywka M, Shutt K, et al. A large outbreak of Clostridium difficile-associated disease with an unexpected proportion of deaths and colectomies at a teaching hospital following 
increased fluoroquinolone use. Infect Control Hosp Epidemiol. 2005; 26:273. [PubMed: 15796280]

18. Goorhuis A, Van deer Kooi T, Vaessen N, et al. Spread and epidemiology of Clostridium difficile polymerase chain reaction ribotype 027/toxinotype III in The Netherlands. Clin Infect Dis. 2007; 45:695-703. [PubMed: 17712752]

19. Goorhuis A, Bakker D, Corver J, et al. Emergence of Clostridium difficile infection due to a new hypervirulent strain, polymerase chain reaction ribotype 078. Clin Infect Dis. 2008; 47:11621170. [PubMed: 18808358]

20. Bauer MP, Notermans DW, van Benthem BH, et al. Clostridium difficile infection in Europe: a hospital-based survey. Lancet. 2011; 377:63-73. [PubMed: 21084111]

21. Dubberke ER, Olsen MA. Burden of Clostridium difficile on the healthcare system. Clin Infect Dis. 2012; 55(suppl2):S88-S92. [PubMed: 22752870]

22. Finney JMT. Gastro-enterostomy for cicatrizing ulcer of the pylorus. Bull Johns Hopkins Hosp. $1893 ; 4: 53$.

23. Hall IC, O'Toole E. Intestinal flora in new-born infants: with a description of a new pathogenic anaerobe, Bacillus difficilis. Am J Dis Child. 1935; 49:390-402.

24. Rosseau C, Poilane I, De Pontual LC, et al. Clostridium difficile carriage in healthy infants in the community: a potential reservoir for pathogenic strains. Clin Infect Dis. 2012; 55:1209-1215. [PubMed: 22843784]

25. Loo VG, Poirier L, Miller M, et al. A predominately clonal multi-institutional outbreak of Clostridium difficile-associated diarrhea with high morbidity and mortality. N Engl J Med. 2005; 353:2442-2449. [PubMed: 16322602]

26. Altemeier WA, Hummel RP, Hill EO. Staphylococcal enterocolitis following antibiotic therapy. Ann Surg. 1963; 157:847-857. [PubMed: 14012299]

27. Tedesco FJ, Barton RW, Alpers DH. Clindamycin-associated colitis. A prospective study. Ann Intern Med. 1974; 81:429-433. [PubMed: 4412460]

28. Bartlett JG, Onderonk AB, Cisneros RL. Clindamycin-associated colitis in hamsters: protection with vancomycin. Gasterenterology. 1977; 73:772-776.

29. Rifkin GD, Fekety FR, Silva J Jr. Antibiotic-induced colitis implication of a toxin neutralized by Clostridium sordellii antitoxin. Lancet. 1977; 2:1103-1106. [PubMed: 73011]

30. Larson HE, Price AB. Pseudomembranous colitis: Presence of clostridial toxin. Lancet. 1977; 2:1312-1314. [PubMed: 74727]

31. George WL, Sutter VL, Goldstein EJ, et al. Etiology of antimicrobial-agent-associated colitis. Lancet. 1978; 1:802-803. [PubMed: 85818]

32. Larson HE, Price AB, Honour P, et al. Clostridium difficile and the etiololgy of pseudomembranous colitis. Lancet. 1978; 1:1063-1066. [PubMed: 77366]

33. Gerding DN. Clostridium difficile 30 years on: what has, or has not, changed and why? International Journal of Antimicrobial Agents. 2009; 33(Suppl 1):S2-S8. [PubMed: 19303564]

34. Redelings MD, Sorvillo F, Mascola L. Increase in Clostridium difficile-related mortality rates, United States, 1999-2004. Emerging Infectious Diseases. 2007; 13:1417-1419. [PubMed: 18252127]

35. Kazakova SV, Ware K, Baughman B, et al. A hospital outbreak of diarrhea due to an emerging epidemic strain of Clostridium difficile. Arch Intern Med. 2006; 166:2518-2524. [PubMed: 17159019]

36. Labbé AC, Poirier L, MacCannell D, et al. Clostridium difficile infections in a Canadian tertiary care hospital before and during a regional epidemic associated with the BI/NAP1/027 strain. Antimicrob Agents Chemother. 2008; 52:3180-2187. [PubMed: 18573937]

37. Smith A. Outbreak of Clostridium difficile infection in an English hospital linked to hypertoxinproducing strains in Canada and the U.S. Eur Surveill. 2005; 10:E050630.2.

38. Kuijper EJ, van den Berg RJ, Debast S, et al. Clostridium difficile ribotype 027, toxinotype III, the Netherland. Emerg Infect Dis. 2006; 12:827-830. [PubMed: 16704846]

39. Kuijper EJ, Coignard B, Tüll P, et al. Emergence of Clostridium difficile-associated disease in North America and Europe. Clin Microbiol Infect. 2006; 12(Suppl6):2-18. [PubMed: 16965399] 
40. Elixhauser, A.; Steiner, C.; Gould, C. [Accessed 8 January 2013.] Readmissions following hospitalizations with Clostridium difficile infections, 2009. Healthcare Cost and Utilization Project, Agency for Healthcare Research and Quality. Statistical brief \#145. Availalbe at http:// www.hcup-us.ahrq.gov/reports/statbriefs/sb145.pdf

41. Wilcox MH, Shetty N, Fawley WN, et al. Changing epidemiology of Clostridium difficile infection following the introduction of a national ribotyping-based surveillance scheme in England. Clin Infect Dis. 2012; 55:1056-1063. [PubMed: 22784871]

42. Cohen SH, Gerding DN, Johnson S, et al. Clinical practice guidelines for Clostridium difficile infection in adults: 2010 update by the society of healthcare epidemiology of America (SHEA) and the infectious diseases society of america (IDSA). Infect Control Hosp Epidemiol. 2010; 31:431455. [PubMed: 20307191]

43. Miniño, AM.; Xu, JQ.; Kochanek, KD. Natl Vital Stat Rep. Hyattsville, MD: National Center for Health Statistics; 2010. Deaths: preliminary data for 2008; p. 59Available at: http://www.cdc.gov/ nchs/data/nvsr/nvsr59/nvsr59_02.pdf [Accessed 22 February 2013.]

44. Lessa FC, Gould CV, McDonald LC. Current status of Clostridium difficile infection epidemiology. Clin Infect Dis. 2012; 55(supp12):S65-S70. [PubMed: 22752867]

45. Khanna S, Pardi DS, Aronson SL, et al. The epidemiology of community-acquired Clostridium difficile infection: a population-based study. Am J Gastroenterol. 2012; 107:89-95. [PubMed: 22108454]

46. Lessa FC. Community-associated Clostridium difficile infection: How real is it? Anaerobe. 2013 Feb 8. Epub ahead of print.

47. Nylund CM, Goudie A, Garza JM, et al. Clostridium difficile infection in hospitalized children in the United States. Arch Pediatr Adolesc Med. 2011; 165:451-457. [PubMed: 21199971]

48. Zilberberg MD, Tillotson GS, McDonald C. Clostridium difficile infections among hospitalized children, United States, 1997-2006. Emerg Infect Dis. 2010; 16:604-609. [PubMed: 20350373]

49. Khanna S, Baddour LM, Huskins WC, et al. The epidemiology of Clostridium difficile infection in children: a population-based study. Clin Infect Dis. 2013 Feb 13. Epub ahead of print.

50. McDonald LC, Lessa F, Sievert D, et al. Vital Signs: preventing Clostridium difficile infections. MMWR Morb Mortal Wkly Rep. 2012; 61:157-162. [PubMed: 22398844]

51. Campbell RJ, Giljahn L, Machesky K, et al. Clostridium difficile infection in Ohio hospitals and nursing homes during 2006. Infect Control Hosp Epidemiol. 2009; 30:526-533. [PubMed: 19419272]

52. Oake N, Taljaard M, van Walraven $\mathrm{C}$, et al. The effect of hospital-acquired Clostridium difficile infection on in-hospital mortality. Arch Intern Med. 2010; 170:1804-1810. [PubMed: 21059973]

53. Dallal RM, Harbrecht BG, Boujoukas AJ, et al. Fulminant Clostridium difficile: an underappreciated and increasing cause of death and complications. Ann Surg. 2002; 235:363-372. [PubMed: 11882758]

54. Kasper AM, Nyazee HA, Yokoe DS, et al. A multicenter study of Clostridium difficile infectionrelated colectomy, 2000-2006. Infect Control Hosp Epidemiol. 2012; 33:470-476. [PubMed: 22476273]

55. Gravel D, Miller M, Simor A, et al. Health care-associated Clostridium difficile infection in adults admitted to acute care hospitals in Canada: a Canadian nosocomial infection surveillance program study. Clin Infect Dis. 2009; 48:568-576. [PubMed: 19191641]

56. Hubert B, Loo VG, Bourgault AM, et al. A portrait of the geographic dissemination of the Clostridium difficile North American pulsed-field type 1 strain and the epidemiology of Clostridium difficile-associated disease in Quebec. Clin Infect Dis. 2007; 44:238-244. [PubMed: 17173224]

57. Hall AJ, Curns AT, McDonald LC, et al. The roles of Clostridium difficile and Norovirus among gastroenteritis-associated deaths in the United States, 1999-2007. Clin Infect Dis. 2012; 55:216223. [PubMed: 22491338]

58. Hensgens MP, Goorhuis A, Dekkers OM, et al. All-cause and disease specific mortality in hospitalized patients with Clostridium difficile infection: a multicenter cohort study. Clin Infect Dis. 2013 Feb 1. Epub ahead of print. 
59. Black SR, Weaver KN, Jones RC, et al. Clostridium difficile outbreak strain BI is highly endemic in Chicago area hospitals. Infect Control Hosp Epidemiol. 2011; 32:897-902. [PubMed: 21828970]

60. Barbut F, Rupnik M. 027, 078, and Others: Going beyond the numbers (and away from the hypervirulence). Clin Infect Dis. 2012; 55:1669-1672. [PubMed: 22972865]

61. Rupnik M, Wilcox MH, Gerding DN. Clostridium difficile infection: new developments in epidemiology and pathogenesis. Nat Rev Microbiol. 2009; 7:526-536. [PubMed: 19528959]

62. Walk ST, Micic D, Jain R, et al. Clostridium difficile ribotype does not predict severe infection. Clin Infect Dis. 2012; 55:1661-1668. [PubMed: 22972866]

63. McDonald LC. Virulence and clinical outcomes in Clostridium difficile infection: a complex business. Clin Infect Dis. 2012 Dec 21. Epub ahead of print.

64. Walker AS, Eyre DW, Crook DW, et al. Response to Walk et al. "Clostridium difficile ribotype does not predict severe infection”. Clin Infect Dis. 2013 Feb 18. Epub ahead of print.

65. Walk ST, Micic D, Galecki AT, et al. Reply to Walker et al. Clin Infect Dis. 2013 Feb 18. Epub ahead of print.

66. O'Connor JR, Johnson S, Gerding DN. Clostridium difficile infection caused by the epidemic BI/ NAP1/027 strain. Gastrenterology. 2009; 136:1913-1924.

67. McFarland LV. Alternative treatments for Clostridium difficile disease: what really works? J Med Microbiol. 2005; 54:101-111. [PubMed: 15673502]

68. van Nood E, Speelman P, Kuijper EJ, et al. Struggling with recurrent Clostridium difficile infections: is donor faeces the solution? Euro Surveill. 2009; 14:pii=19316.

69. Kelly CP. Can we identify patients at high risk of recurrent Clostridium difficile infection? Clin Microbiol Infec. 2012; 18(Suppl 6):21-27. [PubMed: 23121551]

70. Johnson S. Recurrent Clostridium difficile infection: a review of risk factors, treatments, and outcomes. J Infect. 2009; 58:403-410. [PubMed: 19394704]

71. Drekonja DM, Amundson WH, DeCarolis DD, et al. Antimicrobial use and risk for recurrent Clostridium difficile infection. Am J Med. 2011; 124:1081.e1-1081.e7. [PubMed: 21944159]

72. Chang JY, Antonopoulos DA, Kalra A, et al. Decreased diversity of the fecal microbiome in recurrent Clostridium difficile-associated diarrhea. J Infect Dis. 2008; 197:435-438. [PubMed: 18199029]

73. Garey KW, Sethi S, Yadav Y, et al. Meta-analysis to assess risk factors for recurrent Clostridium difficile infection. J Hosp Infect. 2008; 70:298-304. [PubMed: 18951661]

74. Didelot X, Eyre D, Cule M, et al. Microevolutionary analysis of Clostridium difficile genomes to investigate transmission. Genome Biol. 2012; 13:R118. [PubMed: 23259504]

75. Pacheco SM, Johnson S. Important clinical advances in the understanding of Clostridium difficile infection. Curr Opin Gastroenterol. 2013; 29:42-48. [PubMed: 23207596]

76. Kelly CP, Pothoulakis C, LaMont JT. Clostridium difficile colitis. N Engl J Med. 1994; 330:257. [PubMed: 8043060]

77. Mullane KM, Miller MA, Weiss K, et al. Efficacy of fidaxomicin versus vancomycin as therapy for Clostridium difficile infection in individuals taking concomitant antibiotics for other concurrent infections. Clin Infect Dis. 2011; 53:440-447. [PubMed: 21844027]

78. Tannock GW, Munro K, Taylor C, et al. A new macrocyclic antibiotic, fidaxomicin (OPT-80), causes less alterations to the bowel microbiota of Clostridium difficile-infected patients than does vancomycin. Microbiology. 2010; 156:3354-3359. [PubMed: 20724385]

79. Hensgens MP, Goorhuis A, Dekkers OM, et al. Time interval of increased risk for Clostridium difficile infection after exposure to antibiotics. J Antimicrob Chemother. 2012; 67:742-748. [PubMed: 22146873]

80. Stevens V, Dumyati G, Fine LS, et al. Cumulative antibiotic exposures over time and the risk of Clostridium difficile infection. Clin Infect Dis. 2011; 53:42-48. [PubMed: 21653301]

81. Johnson S, Samore MH, Farrow KA, et al. Epidemics of diarrhea caused by a clindamycinresistance strain of Clostridium difficile in four hospitals. N Engl J Med. 1999; 341:1645.

[PubMed: 10572152] 
82. Carignan A, Allard C, Pépin J, et al. Risk of Clostridium difficile infection after perioperative antibacterial prophylaxis before and during an outbreak of infection due to a hypervirulent strain. Clin Infect Dis. 2008; 46:1838-1843. [PubMed: 18462108]

83. Kuntz JL, Yang M, Cavanaugh J, et al. Trend in Clostridium difficile infection among peripartum women. Infect Control Hosp Epidemiol. 2010; 31:532-534. [PubMed: 20350150]

84. Shaughnessy MK, Amundson WH, Kuskowski MA, et al. Unnecessary antimicrobial use in patients with current or recent Clostridium difficile infection. Infect Control Hosp Epidemiol. 2013; 34:109-116. [PubMed: 23295554]

85. Janarthanan S, Ditah I, Adler DG, et al. Clostridium difficile-associated diarrhea and proton pump inhibitor therapy: a meta-analysis. Am J Gastroenterol. 2012; 107:1001-1010. [PubMed: 22710578]

86. Kwok CS, Arthur AK, Anibueze CI, et al. Risk of Clostridium difficile infection with acid suppressing drugs and antibiotics: meta-analysis. Am J Gastroenterol. 2012; 107:1011-1019. [PubMed: 22525304]

87. United States Department of Health and Human Services. [Accessed February 20, 2013.] FDA Drug Safety Communication: Clostridium difficile-associated diarrhea can be associated with stomach acid drugs known as proton pump inhibitors (PPIs). Available at http://www.fda.gov/ drugs/drugsafety/ucm290510.htm

88. Thorens J, Froehlich F, Schwizer W, et al. Bacterial overgrowth during treatment with omperazole compared with cimetidine: a prospective randomized double blind study. Gut. 1996; 39:54-59. [PubMed: 8881809]

89. Jump RL, Pultz MJ, Donskey CJ. Vegatative Clostridium difficile survives in room air on moist surfaces and in gastric contents with reduced acidity: a potential mechanism to explain the association between proton pump inhibitors and C. difficile-associated diarrhea? Antimicrob Agents Chemother. 2007; 51:2883-2887. [PubMed: 17562803]

90. Williams C. Occurrence and significance of gastric colonization during acid-inhibitory therapy. Best Pract Res Clin Gastroenterol. 2001; 15:511-521. [PubMed: 11403543]

91. Wilson KH, Sheagren JN, Freter R. Population dynamics of ingested Clostridium difficile in the gastrointestinal tract of the Syrian hamster. J Infect Dis. 1985; 151:355-361. [PubMed: 3968453]

92. Agastya G, West BC, Callahan JM. Omperazole inhibits phagocytosis and acidification of phagolysosomes of normal human neutrophils in vitro. Immunopharmacol Immunotoxicol. 2000; 22:357-372. [PubMed: 10952036]

93. Yoshida N, Yoshikawa T, Tanaka Y, et al. A new mechanism for anti-inflammatory actions of proton pump inhibitors-inhibitory effects on neutrophil-endothelial cell interactions. Aliment Pharmacol Ther. 2004; 14(Suppl 1):74-78. [PubMed: 10807407]

94. Zedtwitz-Liebenstein K, Wenisch C, Patruta S, et al. Omperazole treatment diminishes intra- and extracellular neutrophil reactive oxygen production and bactericidal activity. Crit Care Med. 2002; 30:1118-1122. [PubMed: 12006811]

95. Heidelbaugh JJ, Kim AH, Chang R, et al. Overutilization of proton-pump inhibitors: what the clinician needs to know. Ther Adv Gastroenterol. 2012; 5:219-232.

96. Garey KW, Jiang Z, Ghantoji S, et al. A common polymorphism in the interleukin- 8 gene promoter is associated with an increased risk for recurrent Clostridium difficile infection. Clin Infect Dis. 2010; 51:1406-1410. [PubMed: 21058913]

97. Kyne L, Warny M, Qamar A, et al. Asymptomatic carriage of Clostridium difficile and serum levels of IgG antibody against toxin A. N Engl J Med. 2000; 342:390-397. [PubMed: 10666429]

98. Kyne L, Warny M, Qamar A, et al. Association between antibody response to toxin A and protection against recurrent Clostridium difficile diarrhea. Lancet. 2001; 357:189-193. [PubMed: 11213096]

99. Jian ZD, DuPont HL, Garey, et al. A common polymorphism in the interleukin 8 gene promoter is associated with Clostridium difficile diarrhea. Am J Gastroenterol. 2006; 101:1112-1116. [PubMed: 16573784]

100. Chopra T, Alangaden GJ, Chandrasekar P. Clostridium difficile infection in cancer patients and hematopoietic stem cell transplant recipients. Expert Rev Anti Infect Ther. 2010; 8:1113-1119. [PubMed: 20954878] 
101. Eddi R, Malik MN, Shakrov R, et al. Chronic kidney disease as a risk factor for Clostridium difficile infection. Nephrology. 2010; 15:471-475. [PubMed: 20609100]

102. Raines DL, Lopez FA. Clostridium difficile infection in non-HIV-immunocompromised patients and in HIV-infected patients. Curr Gastroenterol Rep. 2011 Aug.13:344-350. [PubMed: 21541693]

103. Boutros M, Al-Shaibi M, Chan G, et al. Clostridium difficile colitis: increasing incidence, risk factors, and outcomes in solid organ transplant recipients. Transplantation. 2012; 93:1051-1057. [PubMed: 22441318]

104. Dubberke ER, Riddle DJ. Clostridium difficile in solid organ transplant recipients. Am J Transplant. 2009; 9(Suppl 4):s35-s40. [PubMed: 20070693]

105. Navaneethan U, Venkatesh PGK, Shen B. Clostridium difficile infection in inflammatory bowel disease - understanding the evolving relationship. World J Gastroenterol. 2010; 16:4892-4904. [PubMed: 20954275]

106. Kutty PK, Wood CW, Sena AC, et al. Risk factors for and estimated incidence of communityassociated Clostridium difficile infection, North Carolina, USA. Emerg Infect Dis. 2010; 16:197204. [PubMed: 20113547]

107. Dumyati G, Stevens V, Hannett GE, et al. Community-associated Clostridium difficile infections, Monroe county, New York, USA. Emerg Infect Dis. 2012; 18:392-400. [PubMed: 22377231]

108. Rogers MA, Greene MT, Saint S, et al. Higher rates of Clostridium difficile infection among smokers. PLoS One. 2012; 7:e42091. [PubMed: 22848714]

109. Pépin J, Gonazales M, Valiquette L. Risk of secondary cases of Clostridium difficile infection among household contacts of index cases. J Infect Dis. 2012; 64:387-390.

110. Gould LH, Limbago B. Clostridium difficile in food and domestic animals: a new foodborne pathogen? Clin Infect Dis. 2010; 51:577-582. [PubMed: 20642351]

111. McFarland LV, Surawicz CM, Greenberg RN, et al. A randomized placebo controlled trial of Saccharomyces boulardii in combination with standard antibiotics for Clostridium difficile disease. JAMA. 1994; 271:1913-8. [PubMed: 8201735]

112. McFarland LV, Elmer GW, Surawicz CM. Breaking the cycle: treatment strategies for 163 cases of recurrent Clostridium difficile disease. Am J Gastroenterol. 2002 Jul; 97(7):1769-75. [PubMed: 12135033]

113. van Nood E, Vrieze A, Nieuwdorp M, et al. Duodenal infusion of donor feces for recurrent Clostridium difficile. N Eng J Med. 2013 Jan 31.368:407-415.

114. McDonald LC, Coignard B, Dubberke E, et al. Recommendations for surveillance of Clostridium difficile-associated disease. Infect Control Hosp Epidemiol. 2007; 28:140-145. [PubMed: 17265394]

115. Fitzpatrick F, Barbut F. Breaking the cycle of recurrent Clostridium difficile infections. Clin Microbiol Infect. 2012; 18(Suppl 6):2-4. [PubMed: 23121548]

116. Surawicz CM, Brandt LJ, Binion DG, et al. Guidelines for Diagnosis, Treatment, and Prevention of Clostridium difficile Infections. Am J Gastroenterol. 2013 Feb 26. Epub ahead of print. 10.1038/ajg.2013.4

117. Crobach MJ, Dekkers OM, Wilcox MH, et al. European Society of Clinical Microbiology and Infectious Diseases (ESCMID): data review and recommendations for diagnosing Clostridium difficile-infection (CDI). Clin Microbiol Infect. 2009; 15:1053-1066. [PubMed: 19929972]

118. Fong KS, Fatica C, Hall G, et al. Impact of PCR testing for Clostridium difficile on incident rates and potential on public reporting: is the playing field level? Infect Control Hosp Epidemiol. 2011; 32:932-933. [PubMed: 21828981]

119. Wilcox MH. Overcoming barriers to effective recognition and diagnosis of Clostridium difficile infection. Clin Microbiol Infect. 2012; 18(Suppl 6):13-20. [PubMed: 23121550]

120. Longtin Y, Trottier S, Brochu G, et al. Impact of the type of diagnostic assay on Clostridium difficile infection and complication rates in a mandatory reporting program. Clin Infect Dis. 2013; 56:67-73. [PubMed: 23011147]

121. Kaltsas A, Simon M, Unruh LH, et al. Clinical and laboratory characteristics of Clostridium difficile infection in patients with discordant diagnostic test results. J Clin Microbiol. 2012; 50:1303-1307. [PubMed: 22238444] 
Table 1

Patient risk factors for initial and recurrent Clostridium difficile infection

\begin{tabular}{|c|c|}
\hline Risk for initial episode ${ }^{a}$ & Risk for recurrent episode(s) ${ }^{a}$ \\
\hline Advanced age ( $\ 65$ years $)^{42,70}$ & Advanced age ( $\succeq 65$ years) $69,70,73$ \\
\hline Antibacterial therapy $2,42,70,71,76,79-82$ & Antibacterial therapy ${ }^{69-71,73,79}$ \\
\hline Cancer chemotherapy ${ }^{42,100}$ & Gastric acid suppressing agents $42,70,73,85-88$ \\
\hline Enteral feeding and gastrointestinal surgery ${ }^{42}$ & Healthcare exposure ${ }^{42,50,69,70,75}$ \\
\hline Gastric acid suppressing agents ${ }^{42,70,85-88}$ & Impaired immune response ${ }^{96-98}$ \\
\hline Healthcare exposure ${ }^{42,50,70,75}$ & Previous episode(s) of $\mathrm{CDI}^{20,111,112}$ \\
\hline $\begin{array}{l}\text { Impaired immune response }{ }^{42,70,96-98} \\
\text { Smoking and history of smoking }{ }^{108} \\
\text { Underlying chronic comorbidities } \\
64,101-105\end{array}$ & Underlying chronic comorbidities 69 \\
\hline
\end{tabular}

${ }^{a}$ Listed alphabetically 